\title{
IAEA SAFETY STANDARDS ON MANAGEMENT SYSTEMS AND SAFETY CULTURE
}

\author{
Kerstin Dahlgren Persson \\ International Atomic Energy Agency, Department of Nuclear Energy \\ P.O. Box 100, A-1400 Vienna, Austria
}

\begin{abstract}
IAEA SAFETY STANDARDS ON MANAGEMENT SYSTEMS AND SAFETY CULTURE. The IAEA has developed a new set of Safety Standards for applying an integrated Management System for facilities and activities. The objective of the new Safety Standards is to define requirements and provide guidance for establishing, implementing, assessing and continually improving a Management System that integrates safety, health, environmental, security, quality and economic related elements to ensure that safety is properly taken into account in all the activities of an organization. With an integrated approach to management systems it is also necessary to include the aspect of culture, where the organizational culture and safety culture is seen as crucial elements of the successful implementation of this management system and the attainment of all the goals and particularly the safety goals of the organization. The IAEA has developed a set of services aimed at assisting it's Member States in establishing, implementing, assessing and continually improving an integrated management system.
\end{abstract}

Keywords : Safety Standards, Safety Culture, Management System

\section{INTRODUCTION}

The IAEA support to Member States regarding application of safety, technological and engineering best practices included the development of an extensive number of publications related with quality management/ assurance, issued in the Safety Standards, Safety Reports, Technical Report and Technical Document (TECDOC) Series.

Recently, the IAEA developed a new set of Safety Standards that establishes requirements and provide guidance for applying an integrated Management System for facilities and activities. The new standards replace the IAEA 50-C-Q Code on Quality Assurance for Safety in Nuclear Power Plants and other Nuclear Installations, as well as the related 14 Safety Guides contained in the Safety Series No.50-C/SG-Q (1996) [1]. This code and developments within the International Organization for Standardization (ISO) ISO 9001:2000 [2] and ISO14001: 1996 [3] publications were considered in developing this comprehensive, integrated set of Management System requirements. Member States experience in developing, implementing and improving Management Systems was also taken into account. 
The aim of the new set of Safety Standards is to provide requirements and guidance for implementing an effective Management System that:

1. Integrates all aspects of managing nuclear installations and activities including the safety, health, environmental, security, quality and economic requirements in a coherent manner,

2. Promotes continual improvement,

3. Describes the planned and systematic actions necessary to provide adequate confidence that all these requirements can be satisfied, and

4. Supports the enhancement and improvement of organizational and safety culture.

The integration aims to ensure that economic, environmental, health, security and quality matters are not considered separately to safety matters, to avoid any potential negative impact on safety. The three main elements of the management system safety standards are:

1. Safety Requirements GS-R-3 [4] specifies the Management System requirements for all nuclear installations and activities that are based on the Code 50-C-Q and other relevant international standards. It was published in 2006.

2. The Safety Guide GS-G-3.1 [5] provides thematic guidance for each of the requirements contained in GS-R-3 and applicable to all nuclear facilities and activities. GS-G-3.1 will include all of the relevant guidance material that is contained in current Safety Guides 50-SG-Q1 to Q7 as well as new material. It was published in 2006.

3. Draft Safety Guide (DS349) [6] will provide specific guidance for Management Systems for nuclear facilities. It will include all of the relevant guidance material that is contained in current Safety Guides 50-SG-Q8- Q14 as well as new material. The expected publication is 2007 .

\section{FROM TRADITIONAL QA TOWARDS INTEGRATED MANAGEMENT SYSTEMS}

The technological innovations have radically altered the relationship between systems and humans and therefore the way to manage the whole organization. The issues related with complex activities and multiple objectives involve people operating at different levels in the organization. The operating processes are modified by the introduction of new management practices and new requirements. The daily practices and the results achieved by the 
organization, the organizational culture and the management processes are deeply interrelated. The way to manage the organization has had to evolve accordingly to accommodate these changes and to ensure that the employees understand what has to be done to meet all requirements. The model illustrated below [5] tries to represent the evolution over the last century regarding the approaches applied by organizations in order to achieve good safety standards and performance. The reality is undoubtedly more detailed and complex. Many initiatives have often been introduced in parallel and new initiatives have co-existed with former initiatives. The important message that the model delivers is that the activity of managing an organization and surviving has been evolving to continually strive for higher levels of performance and safety and that this trend is ongoing. The model marks only some of the key management approaches:

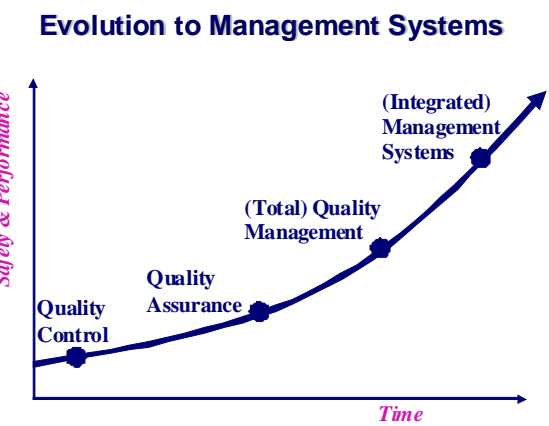

Figure 1. Evolution to management systems.

- Quality Control sorted the conforming products from the nonconforming at the end of the process. Mostly consisted of some type of inspections/measurements for yes or not acceptance.

- Quality Assurance took measures to systematically prevent nonconformances by using established procedures and documentation to demonstrate that quality was implemented throughout the production process. The Quality Assurance approach has also evolved from a compliance approach to one of a more performance based focus.

- Quality Management introduced the consideration of everyone involved within the process and the concept of internal customer and supplier. This was a relevant development bringing attention to organization being essentially about people and recognition of the organizational culture issue. Business excellence models appeared. 
- Management System integration was the development where the organizations became increasingly aware that other stakeholders, apart form just their customers and employees, had to be addressed while conducting their business. Organizations put increasing attention on issues such as the safety, health, quality, environment, finance, security, human resources, cultural aspects, etc, and aimed to manage the totality by using an integrated Management System aimed at meeting the totality of their objectives. Integrating the Management System leads to a coherent, harmonious and optimal way of delivering the vision of top management and the goals and objectives of the organization.

The model also suggests that an integrated Management System is not the final solution in the evolution. The continuing path and need for higher levels of performance and safety will further evolve. It is therefore important to remain flexible in order to be able to dynamically adjust to the increasing changing and challenging demands. An idealized end point could be envisaged; where a full recognition that the human being is the ultimate source of quality and safety. This ideal end point might then be described in a single and short statement: "Do the things right the first time, and apply continual improvement afterwards".

\section{MANAGEMENT SYSTEMS AND CULTURE}

When developing the new set of IAEA Safety Standards for Management Systems it was recognized at an early stage that with an integrated approach to management systems it was necessary to include the aspect of culture. With an integrated approach, the aspects of the management system that define processes and practices need to be combined with people's values, attitudes and behaviours in order for the organization to fully reach it's goals and objectives.

Today, nuclear organizations are also facing many new challenges that require that they will be able to continually change and improve in order to survive in a more competitive environment. There are numerous examples of how organizations have failed to improve organizational effectiveness through new management strategies due to the fact that the change and improvement efforts did not consider the impacts of the organizational culture.

The management system will both influence and be influenced by the overall culture of the organization. 
In order to achieve desired outcomes it is necessary to consider the formal processes and strategies of the organization and at the same time recognize that they have been produced based on the thinking prevalent in the organizational culture. The way in which the management system is implemented will in turn have an impact on the values, attitudes, and behaviours of the members of the organization i.e. the organization's culture.

For a nuclear organization an integrated approach to the achievement of all the goals of the organization should be addressed in a way that ensures that safety is not compromised. Therefore the management system should provide structure and direction to the organization in a way that promotes and enables the development of a strong safety culture together with the achievement of high levels of safety performance.

In the new IAEA Safety Standards on Management Systems for Facilities and Activities the generic Requirements [4] have been formulated as follows: " The management system shall be used to promote and support a strong safety culture by:

- Ensuring a common understanding of the key aspects of safety culture within the organization;

- Providing the means by which the organization supports individuals and teams to carry out their tasks safely and successfully, taking into account the interaction between individuals, technology and the organization;

- Reinforcing a learning and questioning attitude at all levels of the organization;

- Providing the means by which the organization continually seeks to develop and improve its safety culture.

\section{WHAT IS ORGANIZATIONAL CULTURE AND SAFETY CULTURE?}

Last year we were reminded of the fact that twenty years has passed since the accident at the Chernobyl plant. It was in the IAEA investigation report that followed upon this accident that the term "Safety Culture" was introduced for the first time to the nuclear community. While intended to describe how the thinking and behaviours of people in the organization with regard to safety contributed to the accident it also created a need to further define and describe what was really meant by this concept. A further clarification of the concept came in the report by the International Nuclear Safety Advisory Group to the IAEA [8]. They maintained that the establishment of a safety culture within an organization is 
one of the fundamental management principles necessary for the safe operation of a nuclear facility. The definition they presented recognized that safety culture is both structural and attitudinal in nature and relates to the organization and its style, as well as to attitudes, behaviours and the commitment of individuals at all levels in the organization.

Since the introduction of the concept of safety culture the IAEA has broadened it's perspective further with attention focused on obtaining a deeper understanding of the actual concept of culture and particularly organizational culture. The IAEA guidance documents and support services has reflected the needs of Member States to first get a better understanding of the concept itself, then how to assess, enhance and continuously improve and sustain a strong safety culture particularly during times of change [9-13]. The latest developments have been the integrated approach to management systems where the organizational culture and safety culture is seen as crucial elements of the successful implementation of this system and the attainment of all the goals and particularly the safety goals of the organization.

There are many ways in which the culture of an organization has been described. A common phrase used is "it's the way we do things around here", which provides unwritten and often unspoken guidelines for how to get along in the organization, a sense of identity to employees. It reflects what is valued, the dominant managerial and leadership styles, the language, the procedures and routines, and the definitions of success.

Another way to understand culture is to realize that it exists at several "levels" and that we must endeavour to understand the different levels, but especially the deeper levels. A three-level model, consisting of "artefacts", "espoused values" and "basic assumptions" has been proposed when studying organizational culture [14], which can be applied to safety culture as well. These levels of culture go from the very visible to the tacit and invisible. Examples of visible safety culture artefacts are the documented management system with safety policy statements and behaviours such as management's visible commitment to safety and things like the use of safety equipment. The guiding principles at the espoused level are those values stated by management such as "safety is top priority". Key basic assumptions for safety culture is, for example, how the relationship between safety and production is seen - do they go hand in hand or is safety considered a cost; and do people consider the hazards in a way that they believe they are vulnerable to an unexpected event, that "it can happen here". It is these basic 
assumptions that ultimately will determine how people will think and act in relation to safety issues.

\section{MISUNDERSTANDINGS OF SAFETY CULTURE}

Although there has been a lot of work initiated world-wide regarding safety culture, there are still some misunderstandings and even misuse of the concept. We can, for example, see a tendency to classify all events or incidents where human errors have occurred as signs of poor safety culture. However, human errors can occur even within good safety cultures due to the interaction of various factors at a particular point in time. For example, we know that human performance is poor during the night due to the influence of human circadian (24-hour) rhythms and the probability of human error therefore is higher during this time. Therefore, a human error at this time of day doesn't have to be a sign of poor safety culture. But, if safety critical tasks are scheduled to this time of the day, this may be associated with a poor safety culture.

Another common misconception is that you can totally lack a safety culture. There is always an organizational culture in an organization and with safety as a primary goal in a nuclear organization there will always be a safety culture that has developed. The issue is whether it is the one you want, whether it is functional or dysfunctional in reaching the safety goals. Also, the culture is something that is shared among groups of individuals and not a characteristic of single individuals. It is something that members of the organization learn over time as the correct or wrong way of behaving in their organization.

\section{HOW CAN A CULTURE AND SAFETY CULTURE BE CHANGED OR IMPROVED?}

A culture is learned and is particularly influenced by how the leaders of the organization behave and act and the values they communicate. The leader's role is to 1) define reality: where are we today? 2) define the vision: where do we want to be? and 3) define how to get there. You then need to know what characteristics and attributes you want to see in the workplace, and what you want the culture to achieve.

In the new generic Safety Guide [5] of IAEA Safety Standards for Management Systems a set of characteristics and their corresponding attributes for safety culture have been defined. The main characteristics are illustrated in the following figure: 


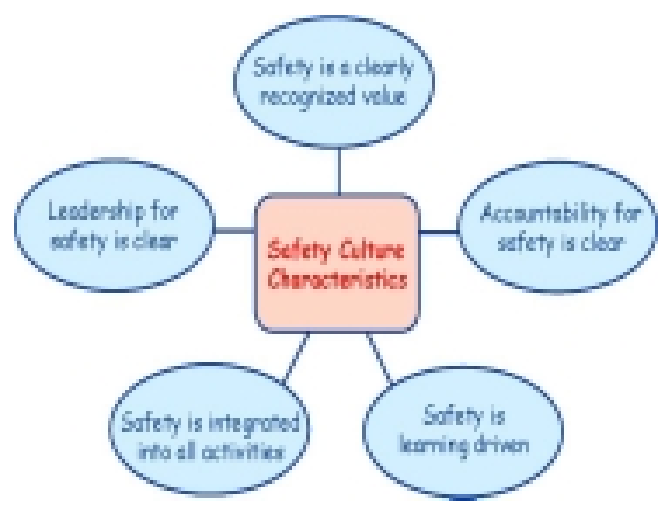

Figure 2. safety culture characteristics.

Each of the 5 safety culture characteristics are further specified by attributes (not presented here). To begin with, any organization wanting to understand their safety culture and seek for areas for improvement can start by reviewing these characteristics and attributes in order to identify where its strengths and weaknesses are.

\section{CONCLUSION}

It is concluded that the IAEA support to continual improvement of management systems, culture and safety culture. The IAEA has developed a set of services aimed at assisting it's Member States in establishing, implementing, assessing and continually improving an integrated management system based on best international practices and standards, including the IAEA Safety Standards, and other relevant IAEA guidance documents. The services include support to the enhancement of the management system based on self-assessments, and/or external assessments by an IAEA expert team.

\section{REFERENCES}

1. International Atomic Energy Agency, Quality Assurance for Safety in Nuclear Power Plants and Other Nuclear Installations, Code and Safety Guides Q1-Q14, Safety Series No. 50-C/SGQ, IAEA, Vienna, Austria (1996).

2. International Organization for Standardization, Quality Management Systems: Requirements, ISO 9001:2000, ISO, Geneva, Switzerland (2000). 
3. International Organization for Standardization, Environmental Management Systems: Specification with Guidance for Use, ISO14001:1996, ISO, Geneva, Switzerland (1996).

4. International Atomic Energy Agency, The Management System for Facilities and Activities, IAEA Safety Standards Series No. Gs-R-3, IAEA, Vienna, Austria (2006).

5. International Atomic Energy Agency, Application of The Management System for Facilities and Activities, IAEA Safety Standards Series No. Gs-G-3.1, IAEA, Vienna, Austria (2006).

6. International Atomic Energy Agency, Application of the Management System for Nuclear Facilities, IAEA Draft Safety Standard, Vienna, Austria.

7. M. Korteweg and I. Dalling, Integrated Management, The Next Evolutionary Step? The Institute of Quality Assurance, IQA (www.iqa.org).

8. International Nuclear Safety Advisory Group, Safety Culture, Safety Series No. 75-INSAG-4, IAEA, Vienna, Austria (1991).

9. International Atomic Energy Agency, Developing Safety Culture in Nuclear Activities, Practical Suggestions to assist Progress, Safety Reports Series No. 11, IAEA, Vienna, Austria (1998).

10. International Atomic Energy Agency, Safety Culture in Nuclear Installations, IAEA-TECDOC-1329, Vienna, Austria (2002).

11. International Atomic Energy Agency, Self-Assessment Of Safety Culture in Nuclear Installations, Highlights and Good Practices, IAEA-TECDOC-1321, Vienna, Austria (2002).

12. International Nuclear Safety Advisory Group, Management of Operational Safety in Nuclear Power Plants, INSAG-13, IAEA, Vienna, Austria (1999).

13. International Nuclear Safety Advisory Group, Key Practical Issues in Strengthening Safety Culture, INSAG-15, IAEA, Vienna, Austria (2002).

14. E. Schein., Organizational Culture and Leadership, Jossey-Bass Inc. (1992). 